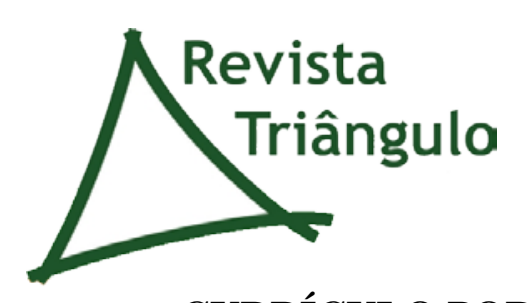

Uberaba, v. 5, n. 2, p. 03-21, jul./dez. 2012. ISSN: 2175-1609

\title{
CURRÍCULO POR PROJETOS NO ENSINO SUPERIOR: DESDOBRAMENTOS PARA A INOVAÇÃO E QUALIDADE NA DOCÊNCIA ${ }^{1}$
}

\section{PROJECT - BASED CURRICULUM IN HIGHER EDUCATION: DEVELOPMENTS FOR INNOVATION AND QUALITY IN TEACHING}

Elize Keller-Franco $^{2}$, Marcos Tarciso Masetto ${ }^{3}$

\footnotetext{
${ }^{1}$ Artigo adaptado do texto apresentado no VII Congresso Iberoamericano de Docência Universitária: Ensino Superior - Inovação e qualidade na docência, realizado na Faculdade de Psicologia e de Ciências da Educação da Universidade do Porto, Portugal, em 2012.

${ }^{2}$ Centro Universitário Adventista de São Paulo.E-mail: elizekeller@gmail.com

${ }^{3}$ Pontifícia Universidade Católica de São Paulo. E-mail: mmasetto@gmail.com
} 


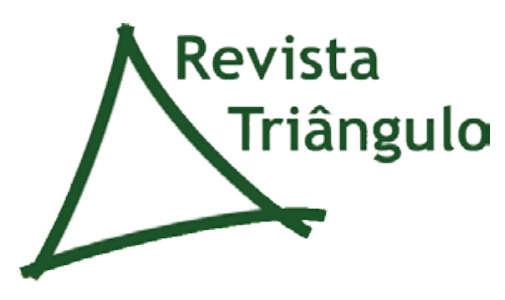

Uberaba, v. 5, n. 2, p. 03-21, jul./dez. 2012. ISSN: 2175-1609

\title{
RESUMO
}

A reflexão proposta neste trabalho está dirigida para as relações entre currículo, qualidade da docência e inovação nas formas de ensinar e aprender no ensino superior. Consideramos neste trabalho a possibilidade de que o paradigma técnico-linear disciplinar, ainda dominante no cenário educacional, vem se mostrando inadequado para articular o conjunto de alterações necessárias à inovação na educação superior, colocando como desafio a necessidade de buscar modelos curriculares construídos sob novas bases. Frente a isso, colocamos a questão que orienta esta discussão: quais as possibilidades de um currículo por projetos se constituir em uma inovação na educação superior e promover novas maneiras de trabalho e ação docente? A discussão em torno dessa questão tem como base um estudo exploratório descritivo analítico de abordagem qualitativa constituído de um estudo teórico sobre currículo e projetos e uma pesquisa de campo que teve como cenário a Universidade Federal do ParanáUnidade Litoral, instituição que vem desenvolvendo uma organização curricular alternativa e uma proposta pedagógica fundamentada em projetos. O estudo teórico deu origem às categorias analíticas e a pesquisa de campo orientou as categorias empíricas.. A triangulação das categorias analíticas com as categorias empíricas trouxe indicadores da viabilidade de uma organização curricular por projetos se constituir em uma inovação na educação superior e orientar novos modos de trabalho e ação docente ao ser capaz de articular um conjunto de elementos apontados como relevantes para uma nova práxis nesse nível de ensino.

Palavras-chave: Educação Superior. Currículo por Projetos. Inovação Educacional.

\begin{abstract}
The reflection proposed in this work is directed to the relationship between curriculum, quality of teaching and innovation in the forms of teaching and learning in higher education. We consider the possibility that the technical-linear-disciplinary curricular paradigm is proving inadequate to articulate a set of proposed changes to innovation in higher education, putting a challenge the need to seek curricular models built on new foundations. Facing that, we put the question that guides this discussion: what is the possibility of a curriculum by projects constitute an innovation in higher education and promote new ways of working and teaching activities? The discussion on this issue is based on an exploratory, descriptive qualitative analytical approach consisting of a theoretical study on curriculum and projects and a field research that had as a backdrop the Federal University of Paraná-Unit Litoral, an institution that has developed an alternative curricular organization and a project-based pedagogical proposal. The theoretical study gave rise to the analytical categories and the field research guided the empirical categories. The triangulation of empirical and analytical categories bring indicators of the viability of a curricular organization by projects constitute itself as an innovation in higher education and guide new ways of working and teaching activities because it is able to articulate a set of elements identified as relevant to a new practice in this level of education.
\end{abstract}

Key words: High Education. Project-based Curriculum. Educational Innovation. 


\section{Revista
Triângulo}

Uberaba, v. 5, n. 2, p. 03-21, jul./dez. 2012. ISSN: 2175-1609

\section{INTRODUÇÃO}

As últimas décadas têm presenciado profundas alterações nas esferas ambiental, profissional, política, econômica e social, desafiando as instituições e, em especial, as instituições educacionais, a uma constante análise e revisão das suas concepções e processos.

No âmbito do Ensino Superior, assiste-se a um esgotamento dos seus modelos pedagógicos. Tem sido recorrente a denúncia de que as instituições universitárias não vêm atendendo de modo eficaz à formação geral constituída de conhecimentos, habilidades e atitudes relevantes para a formação científica e cultural do aluno, nem à formação profissional que integra as capacidades técnicas da ocupação aos valores éticos e humanísticos exigidos pela sociedade atual.

Tais desafios e necessidades têm trazido a temática da inovação para o centro dos discursos e debates, no entanto esse conceito tem sido usado sem uma definição clara e consensual. A inovação na educação superior tem sido proposta e defendida sob diferentes e até contraditórias bases e direcionamentos. Para alguns, a chave da educação para o futuro está na tecnologia. A escola como é hoje deixaria de existir, a educação passaria a acontecer a qualquer hora e lugar em centros virtuais de aprendizagem. Outros segmentos defendem a inovação na lógica do mercado, nos quadros da política do emprego e da qualificação profissional. Propõem para o estado o papel de criar e divulgar indicadores de qualidade para a avaliação das instituições na lógica da competição e do ranqueamento. Outra corrente tem proposto a inovação na linha formativa, no quadro de uma abordagem crítica, acolhendo iniciativas e alternativas organizacionais, curriculares e pedagógicas dentro de um contrato educativo que valorize possibilidades de crescimento pessoal e desenvolvimento profissional.

Debaixo dos mais diferentes pressupostos, a inovação ora se apresenta em proposições fundamentadas na racionalidade técnica, ora na visão crítica, em outros momentos nas características da modernidade ou da pós-modernidade, ou mais recentemente na linha da globalização e da internacionalização das universidades. Em alguns casos, apresenta-se ainda na perspectiva de mudanças pontuais, como alterações na metodologia, no 


\section{Revista
Triângulo}

Uberaba, v. 5, n. 2, p. 03-21, jul./dez. 2012. ISSN: 2175-1609

sistema de avaliação, com a introdução de recursos tecnológicos de ponta e de disciplinas com novas nomenclaturas, ou outros aspectos isolados. (MASETTO, 2011)

Atualmente, um crescente número de estudiosos tem se dedicado ao estudo da inovação. Fazemos parte de um grupo de pesquisa sediado no programa de pós-graduação em educação: currículo da Pontifícia Universidade Católica. O grupo "Formação de Professores e Paradigmas Curriculares”, coordenado pelo Prof. Dr. Marcos Masetto, estabeleceu como objetivos investigar projetos inovadores na graduação e aprofundar questões teóricas sobre inovação, currículo e formação de professores.

A partir de estudos bibliográficos, análises documentais, estudos de casos, seminários, pesquisas individuais e coletivas, os membros do grupo têm apresentado trabalhos em eventos e produzido publicações ligadas à temática.

Diante das variadas compreensões, vamos assumir neste trabalho o conceito de inovação adotado pelo grupo:

\footnotetext{
"Inovação na educação superior deveria ser entendida como o conjunto de alterações que afetam pontos chaves e eixos constitutivos da organização do ensino universitário provocadas por mudanças na sociedade ou por reflexões sobre concepções intrínsecas à missão da Educação superior”. (Masetto, 2004, p.197)
}

Acreditamos no caráter aberto da inovação, capaz de adotar múltiplas formas e significados conforme os contextos em que se insere, contudo a concebemos no marco da missão formativa do ensino superior voltada para a formação de profissionais qualificados e de cidadãos solidários e democráticos para uma sociedade similar. Para tal, acredita-se que a inovação deva articular um conjunto de alterações capazes de superar o paradigma conservador que tem marcado o ensino nas instituições superiores.

Neste trabalho nos propomos a pensar a inovação no ensino superior a partir de uma inovação curricular. Trazemos para reflexão uma pesquisa que teve como objetivo analisar o potencial inovador de uma organização curricular por projetos. Na sequência analisamos os desdobramentos de um currículo por projetos para a qualidade na docência. 


\section{Revista
Triângulo}

Uberaba, v. 5, n. 2, p. 03-21, jul./dez. 2012. ISSN: 2175-1609

\section{CURRÍCULO POR PROJETOS: INDICADORES DE INOVAÇÃO}

Ao adentrarmos o século XXI, evidencia-se a necessidade de um novo paradigma educacional. A transição paradigmática tem enfatizado novas finalidades para o ensino superior. Não cabe mais uma universidade voltada para oferecer uma formação profissional na lógica restrita do mercado, apoiada em estruturas curriculares tecnocratas que privilegiam a fragmentação e reprodução do conhecimento, que desconsideram os contextos e as diferentes realidades dos alunos e que vêm gerando apatia em docentes e discentes.

Precisamos pensar a universidade para os atuais e desafiadores tempos. É preciso que não ensinemos apenas as pegadas dos caminhos conhecidos, mas que tenhamos a coragem também de saltar sobre o desconhecido, de buscar a construção de novos caminhos, criando novas pegadas. (CASTANHO, 2002:77).

As mudanças capazes de alterar o paradigma dos currículos e as práticas pedagógicas da educação superior apontam para uma nova perspectiva epistemológica que valoriza a produção do conhecimento; para abordagens integradas do conhecimento, da teoria com a prática, do ensino com a pesquisa e a extensão; para a reorganização dos tempos, espaços e métodos do processo ensino-aprendizagem; para relações dialógicas entre professor e aluno; para concepções e práticas formativas de avaliação; enfim, para um conjunto de alterações que auxilie os alunos a definirem sua identidade e a se desenvolverem como pessoas e profissionais realizados.

De posse desses direcionamentos, temos como desafio investigar organizações curriculares que respondam a tais expectativas. Com base na experiência com o trabalho por projetos e no seu potencial para uma nova cultura de ensino-aprendizagem, conforme referendado na literatura pedagógica, indagamo-nos sobre o potencial de uma organização curricular por projetos para se constituir em uma inovação no Ensino Superior.

No processo de busca de elementos significativos para uma organização curricular por projetos, optou-se por uma abordagem qualitativa de pesquisa e por um estudo exploratório descritivo analítico, compreendendo uma revisão bibliográfica sobre currículo e projetos e a investigação de um fenômeno educacional com base na sua singularidade e na proximidade com a questão orientadora da pesquisa. 


\section{Revista
Triângulo}

Uberaba, v. 5, n. 2, p. 03-21, jul./dez. 2012. ISSN: 2175-1609

Em face dos diferentes usos do trabalho com projetos, em um primeiro momento foise em busca da fundamentação e do significado de projeto enquanto intervenção metodológica a serviço do processo ensino-aprendizagem, para que pudéssemos refletir sobre suas implicações para uma organização curricular por projetos.

O trabalho com projetos não é novo na educação. Podemos situá-lo como uma prática pedagógica que obteve reconhecimento em diferentes momentos e movimentos educacionais. A busca dos fundamentos conceituais da metodologia de projetos nos leva à corrente filosófica do pragmatismo norte-americano e à teoria educacional progressivista. John Dewey (1859 - 1952) foi um dos principais representantes do pragmatismo e W.H. Kilpatrick (18711965) está entre os educadores mais empenhados em aplicar a teoria educacional progressivista à prática escolar, daí o fato de serem considerados os precursores do método de projetos.

Dewey faz uma denúncia do estado de compartimentalização enfrentado pela escola mediante a multiplicação de matérias, cada qual sobrecarregada de fragmentos desconexos, distanciados da vida real, e que deveriam ser assimilados pela repetição. Propõe como alternativa as “ocupações construtivas”, que foram ganhando espaço e tornaram-se conhecidas como projetos. Kilpatrick deu prosseguimento às ideias de Dewey.

Segundo Hernandez (1998), os projetos em sua primeira versão caracterizavam-se pela ideia de partir de uma situação problemática, vincular a aprendizagem ao mundo exterior e oferecer uma alternativa à fragmentação das matérias.

A teoria educacional progressivista perdeu sua influência em meados da década de 1950, consequentemente, os projetos que gozavam de prestígio nessa abordagem educacional também perderam sua influência. Hernández (1998) aponta ainda a racionalidade tecnológica que se configurou como ideologia dominante após a Segunda Guerra como responsável pelo congelamento do uso de projetos.

Para esse autor, os projetos voltaram a despertar interesse a partir da metade dos anos 60 do século XX, ficando conhecidos de forma mais usual pelo nome de "trabalho por temas”. As ideias de Piaget sobre o desenvolvimento da inteligência e sua relação com a aprendizagem de conceitos despertaram a indagação sobre que conceitos aprender e quais os critérios para selecioná-los. Bruner propôs a noção de conceitos-chave que orientariam a 


\section{Revista
Triângulo}

Uberaba, v. 5, n. 2, p. 03-21, jul./dez. 2012. ISSN: 2175-1609

organização de eixos conceituais com o mesmo significado de grandes temas, ou temas aglutinadores.

Essa proposta leva à necessidade de reposicionar os conteúdos das disciplinas e repensar a maneira de abordá-los para que possam favorecer a relação entre conceitos e a transferência para outros contextos. Os projetos ou o trabalho por temas constituíram uma alternativa para abordar essa proposta na sala de aula. A proposta de Bruner desperta a noção de um currículo interdisciplinar, já que várias disciplinas têm conceitos-chave em comum.

Nos anos 90, a metodologia de projetos é revalorizada, pois coincide com as propostas curriculares atuais, que buscam levar o aluno a pensar criticamente, a dar significado à informação ao analisá-la e sintetizá-la, bem como a aplicá-la para planejar ações, resolver problemas, criar novos materiais e ideias, envolvendo-se significativamente na aprendizagem. "Numa proposta relativamente recente, a utilização de projetos num processo pedagógico aparece com o sentido de proposição de uma prática pedagógica crítica, reflexiva e problematizadora.” (BEHRENS, 2004:167).

Muitos dos princípios que se constituíram em fios condutores do trabalho com projetos conservam-se no paradigma educacional atual, como a visão de investigação de uma situação problemática (Dewey e Kilpatrick) e a organização de eixos temáticos (Bruner). Essas têm sido proposições defendidas na atualidade para superar a organização linear e disciplinar do conhecimento. No entanto, ao ser resgatado, o trabalho com projetos adquire uma visão mais ampla, abordando o conhecimento de forma global, integrada e complexa. “A metodologia de projetos readquire pertinência quando abre como pressupostos a visão de totalidade, a conexão das diversas áreas do conhecimento, o espírito crítico reflexivo, a busca da formação para a cidadania e a recuperação do posicionamento ético. (BEHRENS, 2004:165)

Resgatada a origem e o significado do trabalho com projetos, buscou-se localizá-lo enquanto teoria curricular. O diálogo entre o objeto de estudo e o referencial teórico permitiu situar o currículo por projetos num movimento cuja origem se encontra na linha filosófica do pragmatismo e na tendência pedagógica progressivista de Dewey e Kilpatrick, evoluindo na atualidade para uma tendência curricular crítica, organizando-se sob as pressuposições do código curricular integrado. 


\section{Revista
Triângulo}

Uberaba, v. 5, n. 2, p. 03-21, jul./dez. 2012. ISSN: 2175-1609

As teorias críticas surgem no início da década de setenta como uma reação à concepção curricular tradicional, de ênfase tecnicista, burocrática e administrativa, inspirada nos modelos de administração taylorista. A abordagem curricular crítica desloca a ênfase centrada nos aspectos técnicos de como organizar e elaborar o currículo limitado ao âmbito pedagógico, ampliando a análise para uma perspectiva sociológica em suas determinações e conexões com as estruturas econômicas e sociais mais amplas e com as relações de poder.

O currículo integrado tornou-se conhecido a partir de Basil Bersntein. No currículo integrado, as fronteiras entre as áreas do conhecimento são menos nítidas. A organização do conhecimento se dá a partir de uma ideia central relacionadora, em vez de disciplinas isoladas.

A abordagem curricular integrada não subestima o papel das disciplinas, mas propõe novas relações para além da dominante organização disciplinar. Conforme Beane, na integração curricular, “o conhecimento proveniente das disciplinas reposiciona-se no contexto do tema, questões e nas atividades em causa”. (BEANE, 2003:106).

Para Santomé (1998), uma das modalidades mais clássicas de integração curricular se dá por meio do trabalho com projetos.

Localizado dentro de um marco teórico conceitual, à medida que fomos avançando na pesquisa exploratória, as categorias analíticas constituídas do conjunto de elementos inovadores viabilizados em um currículo por projetos foram emergindo.

O processo reflexivo estabelecido no diálogo do referencial teórico com o objeto de estudo revelou que pensar uma inovação curricular por projetos significa relacionar vários fatores, tanto do ponto de vista macro - as políticas educacionais e seus determinantes sociais e econômicos - como do ponto de vista meso - envolvendo a instituição em seus aspectos organizacionais e estruturais -, como, ainda, num nível micro, o espaço da sala de aula.

Nesse sentido, partiu-se da premissa de que uma organização curricular por projetos, para ser capaz de alavancar uma práxis inovadora na educação superior, deve articular a dimensão didático-pedagógica, a dimensão estrutural-organizacional e a dimensão políticocultural. Essas três dimensões deram origem às categorias, cada uma desdobrando-se em subcategorias. 


\section{Revista
Triângulo}

Uberaba, v. 5, n. 2, p. 03-21, jul./dez. 2012. ISSN: 2175-1609

Na dimensão didático-pedagógica se desvelaram como relevantes para um currículo por projetos as seguintes subcategorias: indissociabilidade entre ensino, pesquisa e extensão; relação de parceria entre professor e aluno; relação entre teoria e prática; interdisciplinaridade; conteúdos conceituais procedimentais e atitudinais; avaliação formativa; múltiplos domínios de espaços, tempos e tecnologias; referenciais epistemológicos que valorizam a construção do conhecimento a partir de problematizações sociais concretas; abertura para a comunidade/sociedade como ambiente de problematização e aprendizagem; e metodologia de ensino-aprendizagem fundamentada em projetos.

Uma inovação curricular por projetos não pode ser indiferente às complexas determinações da prática pedagógica, é na esfera micro, no espaço da sala de aula, no âmbito da dimensão didático-pedagógica que o currículo exerce sua maior parcela de ação ao pôr em prática os princípios e traços essenciais de um propósito educativo.

Por outro lado, em função da natureza sócio-formativa do currículo por projetos e do seu marco conceitual fundado nas teorias curriculares críticas e nos pressupostos do currículo integrado, é que este vai além dos aspectos didático-pedagógicos. Por incluir alterações no formato do currículo, superando a lógica tradicional técnico-linear-disciplinar, contempla intervenções a nível meso, no âmbito institucional e nos códigos de estruturação curricular, abarcando a categoria que denominamos de estrutural /organizacional, da qual emergem as seguintes subcategorias: organização curricular por temas, módulos ou grandes eixos; plano de visão; plano de ação.

Essa categoria apresentou-se como fundamental para uma inovação curricular por projetos. Para que um currículo por projetos possa ser implementado, é necessário todo um esforço e apoio institucional na organização do processo ensino-aprendizagem no sentido de superar o paradigma disciplinar tão dominante em nossos currículos. Será necessária também toda uma reflexão prévia, um plano de visão que ofereça uma percepção clara de onde se está aventurando e um plano de ação delineado que oriente as ações dos envolvidos, gerando confiança na viabilização da proposta e tornando-a menos suscetível a resistências.

Dessa forma, foi se apresentando com clareza que a renovação pedagógica através de um currículo por projetos inclui uma dimensão político cultural que configurou a terceira categoria. A perspectiva sociológica da abordagem curricular crítica nos convida a ver o 
Uberaba, v. 5, n. 2, p. 03-21, jul./dez. 2012. ISSN: 2175-1609

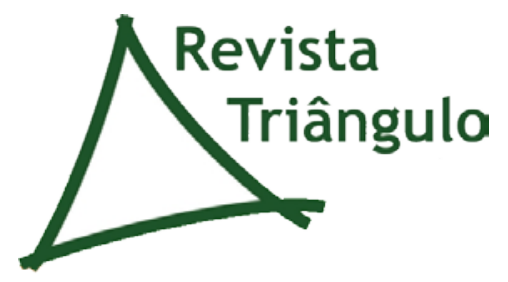

currículo como uma expressão de diversas forças na sociedade. É preciso correlacionar decisões técnico-pedagógicas com os determinantes exteriores à instituição e à aula. Trata-se de incluirmos o nível macro e seus determinantes sociais, políticos e econômicos em suas correlações com os níveis micro e meso.

O currículo por projetos, enquanto teoria curricular crítica, altera e questiona o enfoque político social econômico hegemônico e dirige-se para abordagens emancipatórias do conhecimento e das relações, visando a uma socialização crítica dos indivíduos. Isso implica considerar e rever valores culturais enraizados nos atores envolvidos no processo pedagógico, alterar as formas em que se processam as tomadas de decisão e investir em programas de formação para mudanças culturais e pessoais. Nesse sentido, a categoria político-cultural envolve subcategorias tais como: formação docente; perfil docente; perfil discente; planejamento e gestão participativa; avaliação e acompanhamento da inovação.

O estudo exploratório trouxe indicadores que nos permitem argumentar a favor do currículo por projetos como uma matriz de mudança em potencial para aqueles segmentos da educação que entendem ser necessário recuperar a totalidade do conhecimento e romper com o conservadorismo das práticas pedagógicas repetitivas e acríticas. No entanto, diante da denúncia na literatura de que o nível da prática curricular ainda vem sendo pouco investigado e com a convicção da inter-relação entre teoria e prática, foi-se em busca de um campo empírico que permitisse estabelecer novas relações e aproximações com o objeto de estudo.

A instituição escolhida foi a Universidade Federal do Paraná (UFPR) Unidade Litoral, tendo em vista sua opção por uma organização curricular alternativa e uma proposta pedagógica fundamentada em projetos.

Os dados coletados na pesquisa de campo a partir dos documentos, entrevistas e observações deram origem às categorias e subcategorias empíricas.

A análise comparativa das categorias analíticas e empíricas permite verificar considerável similaridade entre elas. Os indicadores de um currículo organizado por projetos propostos nas categorias e subcategorias analíticas se repetiram nas categorias e subcategorias empíricas, alguns de forma mais evidente, outros de forma mais silenciada. Novos indicadores emergiram na pesquisa de campo, vindo a ampliar as categorias inicialmente propostas, como, por exemplo, a autonomia, antecedentes culturais e a parceria com a 


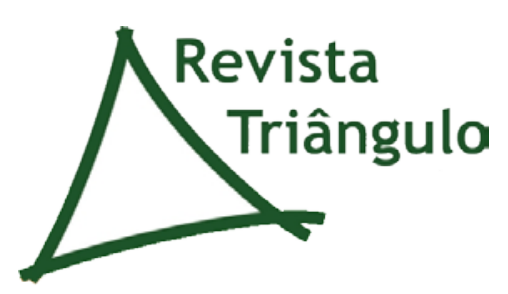

Uberaba, v. 5, n. 2, p. 03-21, jul./dez. 2012. ISSN: 2175-1609

comunidade e instituições sociais e governamentais não previstas inicialmente nas categorias analíticas.

As categorias e subcategorias analíticas e empíricas e a relação entre elas estão representadas no quadro a seguir. As setas sombreadas indicam que foi possível verificar uma forte correlação entre as categorias empíricas e analíticas. As setas pontilhadas significam um nível fraco de evidência da subcategoria no cenário empírico. As subcategorias que aparecem exclusivamente na coluna das subcategorias empíricas foram as que emergiram na pesquisa de campo, vindo a complementar o quadro de categorias proposto inicialmente. Uma descrição e análise mais detalhada sobre os elementos inovadores do currículo por projetos podem ser encontrados em Keller-Franco (2008). 
Uberaba, v. 5, n. 2, p. 03-21, jul./dez. 2012. ISSN: 2175-1609

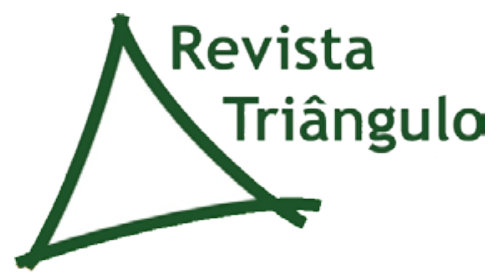

Quadro 1 - Elementos viabilizados em um currículo por projeto

\begin{tabular}{|c|c|c|c|}
\hline Categorias & Subcategorias Analíticas & & Subcategorias Empiricas \\
\hline \multirow{11}{*}{ 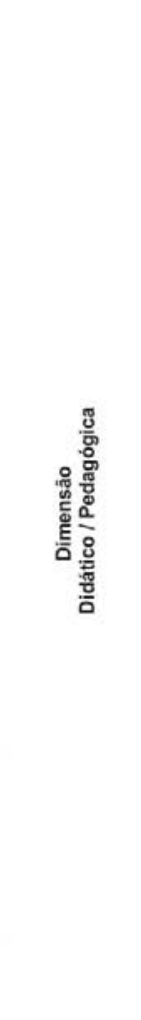 } & $\begin{array}{l}\text { Indissociabilidade entre ensino, } \\
\text { pesquisa e extensão }\end{array}$ & & $\begin{array}{l}\text { Indissociabilidade entre ensino, } \\
\text { pesquisa e extensão }\end{array}$ \\
\hline & Relaçăo entre teoria e prática & $\Leftrightarrow$ & Relação entre teoria e prática \\
\hline & $\begin{array}{l}\text { Metodologia ensino-aprendizagem } \\
\text { fundamentada em projetos }\end{array}$ & $\vec{b}$ & $\begin{array}{l}\text { Metodologia ensino-aprendizagem } \\
\text { fundamentada em projetos }\end{array}$ \\
\hline & Interdisciplinaridade & $\vec{b}$ & Interdisciplinaridade \\
\hline & Avaliçăo Formativa & $\Rightarrow$ & Avaliçăo Formativa \\
\hline & $\begin{array}{l}\text { Conteúdos conceituais } \\
\text { procedimentais e atitudinais. }\end{array}$ & $\Leftrightarrow$ & $\begin{array}{l}\text { Conteúdos conceituais } \\
\text { procedimentais e atitudinais }\end{array}$ \\
\hline & $\begin{array}{l}\text { Múltiplos domínios de espaços, } \\
\text { tempos e tecnologias }\end{array}$ & $\Rightarrow$ & $\begin{array}{l}\text { Múltiplos domínios de espaços, } \\
\text { tempos e tecnologias }\end{array}$ \\
\hline & $\begin{array}{l}\text { Referenciais epistemológicos que } \\
\text { valorizam a construçāo do conhecimento } \\
\text { a partir de problematizaçōes sociais } \\
\text { concretas }\end{array}$ & $\Leftrightarrow$ & $\begin{array}{l}\text { Referenciais epistemológicos que } \\
\text { valorizam a construçāo do conhecimento } \\
\text { a partir de problematizações sociais } \\
\text { concretas }\end{array}$ \\
\hline & $\begin{array}{l}\text { Abertura para a comunidade/sociedade } \\
\text { como ambiente de problematização } \\
\text { e aprendizagem }\end{array}$ & $\Leftrightarrow$ & $\begin{array}{l}\text { Abertura para a comunidade/sociedade } \\
\text { como ambiente de problematização } \\
\text { e aprendizagem }\end{array}$ \\
\hline & $\begin{array}{l}\text { Relaçăo de parceria entre } \\
\text { professor } e \text { aluno }\end{array}$ & \multirow[t]{2}{*}{$\Leftrightarrow$} & $\begin{array}{l}\text { Relação de parceria entre } \\
\text { professor } e \text { aluno }\end{array}$ \\
\hline & & & Autonomia \\
\hline \multirow{5}{*}{ 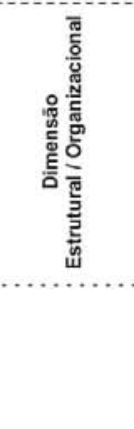 } & Plano de visão & $\Rightarrow$ & Plano de visāo \\
\hline & Plano de ação & $\overrightarrow{3}$ & Plano de açāo \\
\hline & $\begin{array}{l}\text { Organizaçāo curricular por } \\
\text { eixos, módulos ou temas }\end{array}$ & $\Leftrightarrow$ & $\begin{array}{l}\text { Organizaçāo curricular por } \\
\text { eixos, módulos ou temas }\end{array}$ \\
\hline & Formação docente & 8 & Formação docente \\
\hline & $\begin{array}{l}\text { Planejamento e gestão } \\
\text { participativa }\end{array}$ & $\Rightarrow$ & $\begin{array}{l}\text { Planejamento e gestão } \\
\text { participativa }\end{array}$ \\
\hline \multirow{5}{*}{ 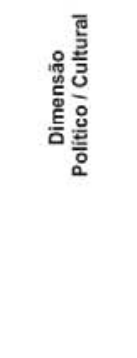 } & Perfil docente & $\vec{b}$ & Perfil docente \\
\hline & Perfil discente & 3 & Perfil discente \\
\hline & $\begin{array}{l}\text { Avaliação } \Theta \text { acompanhamento } \\
\text { da inovação }\end{array}$ & $\Leftrightarrow$ & $\begin{array}{l}\text { Avaliaçāo e acompanhamento } \\
\text { da inovação }\end{array}$ \\
\hline & & & Antecedentes culturais \\
\hline & & & $\begin{array}{l}\text { Parceria com a comunidade e } \\
\text { outras instituiçōes sociais e } \\
\text { governamentais }\end{array}$ \\
\hline
\end{tabular}




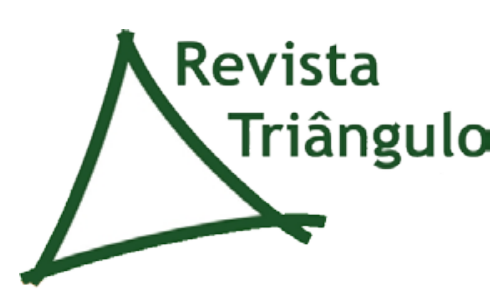

Uberaba, v. 5, n. 2, p. 03-21, jul./dez. 2012. ISSN: 2175-1609

\section{CURRÍCULO POR PROJETOS: DESDOBRAMENTOS PARA A QUALIDADE DA DOCÊNCIA}

Um ponto importante a ser destacado quanto à qualidade da docência é o papel desempenhado pela própria inovação na formação docente. O aperfeiçoamento profissional, e até pessoal, vai ocorrendo à medida que a inovação vai sendo colocada em prática. Esse aspecto se fez sentir nos depoimentos dos professores envolvidos na inovação curricular que pesquisamos:

\footnotetext{
Estou numa universidade que não tem limites para a discussão sobre educação. O que eu faço aqui, em outro lugar teria que pagar para fazer. É uma formação em serviço, é o tempo todo aprendendo. O que eu aprendi com meus colegas, nesse ano e meio que estive aqui, valeu por dez anos. A gente muda em todos os aspectos, isso vai acontecendo de uma forma muito natural. Na verdade a minha modificação é a mesma dos alunos. (ENTREVISTADO $\mathrm{N}^{\circ}$ 7).

O processo de aprendizado é continuo. A gente aprende na sala de aula, na comunidade, com os outros professores, às vezes a gente dá aula com dois ou três professores, o que é muito significativo.( ENTREVISTADO Nº 9 ).
}

Acreditamos que muitas das habilidades requeridas dos professores hoje se tornam inviáveis no paradigma curricular técnico-disciplinar-linear predominante em nossos sistemas educacionais. A especialização e a atuação em parcelas cada vez mais reduzidas do conhecimento levam à desprofissionalização docente e à perda de competências profissionais básicas.

Para Sacristán, os currículos integrados

[...] supõem uma mudança muito decisiva no conceito e conteúdo da profissionalidade docente e, portanto na formação cultural e pedagógica de que os professores necessitarão [...] a primeira conseqüência, pois, é que o professor vê suas competências profissionais ampliadas. (SACRISTÁN, 2000:95).

Um dos desdobramentos significativos do currículo por projetos está em favorecer uma abordagem interdisciplinar do conhecimento. Essa tem sido uma das habilidades mais enfatizadas para o exercício da docência com qualidade e uma da mais frustradas. Para Fazenda (1997), a interdisciplinaridade tem ocupado a palavra de ordem das propostas educacionais, tanto em âmbito local como global. Ressalta, no entanto, que sua premência 


\section{Revista
Triângulo}

Uberaba, v. 5, n. 2, p. 03-21, jul./dez. 2012. ISSN: 2175-1609

tem se dado no campo do discurso, na prática, os educadores sentem-se inseguros e perplexos, sem saber como implementá-la.

Acreditamos que a contradição entre a proposição e a implementação está em buscar viabilizar a interdisciplinaridade em um currículo organizado por disciplinas. Concordamos com Sacristán (2000:81) que será difícil considerar a capacidade de relacionar conteúdos diversos dentro de uma estrutura curricular com conteúdos isolados uns dos outros. Para Masetto (2006:3), “o conceito de interdisciplinaridade apresenta um paradigma de conhecimento e de ciência que ultrapassa o modelo tradicional de se conhecer que é a forma disciplinar”.

O currículo por projetos, enquanto modalidade de currículo integrado, supera a organização curricular fundamentada na separação das disciplinas. $\mathrm{Na}$ proposta que defendemos para o desenho de um currículo por projetos (KELLER-FRANCO, 2008), todo o currículo se estrutura por projetos que estão subordinados a grandes temas ou módulos que funcionam como uma ideia central relacionadora integrando diferentes áreas do conhecimento em suas dimensões conceituais, procedimentais e atitudinais.

O currículo por projetos não desconsidera os conhecimentos disciplinares, mas reorganiza-os de forma a romper com as fronteiras disciplinares e com a fragmentação do conhecimento ao integrar saberes e conceitos-chave de diferentes recortes disciplinares e ampliá-los a partir da consideração e da inclusão de conteúdos do mundo vivencial. Os conceitos de uma disciplina não se esgotam em um semestre, mas se integram ao longo do curso aos conceitos de outras áreas para que possam oferecer uma visão abrangente, contextualizada e significativa para o projeto em causa.

Um currículo assim pensado e organizado favorece uma abordagem interdisciplinar do conhecimento e propicia uma profissionalidade compartilhada, ao valorizar o planejamento e o exercício da docência em equipes de competências diversificadas.

Apresenta-se assim outro importante desdobramento do currículo por projetos favorável à promoção da qualidade da docência: o trabalho em equipe e o professor como gestor do currículo.

A organização do currículo que ultrapassa o âmbito das disciplinas reclama decisões coletivas, que envolvem mais de um professor, quer no planejamento das atividades 


\section{Rriângula}

Uberaba, v. 5, n. 2, p. 03-21, jul./dez. 2012. ISSN: 2175-1609

curriculares, quer na condução das atividades de aprendizagem junto aos alunos. Sacristán (2000) destaca como uma mudança qualitativa as inovações curriculares em que as instituições envolvidas promovem estruturas de funcionamento que favoreçam o trabalho coletivo.

A inovação curricular que pesquisamos (UFPR) oferece oportunidade para o desenvolvimento da profissionalização a partir de um modelo organizativo que favorece a dimensão ativa e coletiva da ação docente. O “currículo em movimento”, como a comunidade educacional o denomina, pareceu-nos privilegiar uma concepção de currículo como "realidade social construída no próprio processo de seu desenvolvimento” (SACRISTÁN, 2000:193).

A proposta não é fechada, apesar de ter entrado posteriormente à criação da universidade, me sinto participante na construção dessa proposta. Não é um projeto pronto acabado, é uma construção permanente. A partir das experiências, das vivências na comunidade e do contato com os alunos, a gente avalia e reconstrói continuamente o projeto. (ENTREVISTADO No 9).

As Câmaras Interdisciplinares e o Conselho Diretivo são estruturas institucionais criadas para se constituírem como espaços privilegiados para a tomada de decisões curriculares coletivas.

As Câmaras são um espaço de participação. São reuniões onde é discutido semanalmente todo o currículo, toda a proposta. O Conselho Diretivo é outro espaço de participação, onde semanalmente, todos os professores discutem e tomam decisões pertinentes a toda dinâmica e organização interna. (ENTREVISTADO No 9).

O referencial teórico e o cenário investigado nos permitem concordar com Pacheco (2002: 195) que “a área de projetos ao nível dos modelos curriculares nos permite identificar condições de cultura escolar que conduzem à colegialidade, à participação, à colaboração e à parceria entre os diversos actores curriculares".

Implicações favoráveis do currículo por projetos para a qualidade da docência encontram-se também no vínculo que estabelece entre ensino, pesquisa e extensão; teoria e prática; educação e sociedade. Estruturas rígidas e compartimentalizadas representam um desafio a uma ação que tenha como intencionalidade a articulação desses aspectos. Cunha (2003) aponta para a lógica curricular tradicional como um dos obstáculos para a viabilização da articulação ensino, pesquisa e extensão. 


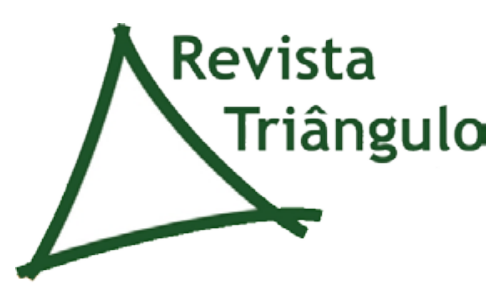

Uberaba, v. 5, n. 2, p. 03-21, jul./dez. 2012. ISSN: 2175-1609

O trabalho com projetos tem como pressuposto a construção do conhecimento, valorizando uma prática pedagógica que parte da realidade e que retorna a essa mesma realidade mediante procedimentos que levam a observar, problematizar, buscar, selecionar e analisar informações, elaborar propostas de intervenção, reconstruir e produzir conhecimento, em um movimento que integra pesquisa, ensino, extensão, teoria e prática.

Na experiência que investigamos, transparece a intencionalidade do vínculo relacional entre educação e sociedade, ensino, pesquisa e extensão mediante uma proposta pedagógica fundamentada em projetos.

\begin{abstract}
Trata-se de uma proposta pedagógica fundamentada no trabalho por projetos que favorece uma forte interação das ações e atividades formativas da instituição com a comunidade e com a realidade regional. Professores, técnicos e estudantes, através de fases sucessivas de conhecimento, compreensão, proposição e ação, desenvolvem projetos de aprendizagem e docência relativos aos desafios enfrentados na região e em sintonia com a população local constroem dialeticamente uma 'profissionalidade' pró-ativa nos educandos e um saber diferenciado que prima pela responsabilidade cidadã nas comunidades envolvidas com a nova proposta. (RELATÓRIO DE ACOMPANHAMENTO DA IMPLANTAÇÃO, 2007:7).

Com os projetos os alunos estão conhecendo melhor a realidade local, a realidade do litoral. No mínimo vai sair daqui um profissional mais identificado com as demandas da sociedade, outros ainda vão levar esse projeto de aprendizado ao nível de projetos sociais. (ENTREVISTADO ${ }^{\circ}$ 6).
\end{abstract}

De acordo com Leite, “os projetos caracterizam-se como uma forma de articulação dos saberes escolares e dos saberes sociais”. (LEITE, MALPIQUE e SANTOS, 2001:57).

A mudança de papel proposta para professores também encontra espaço de viabilização em uma organização curricular por projetos. Trabalhar com projetos demanda ações que levem o professor e o aluno a buscar processos de investigação e pesquisa. $\mathrm{O}$ professor deixa de ser reprodutor e o aluno receptor do conhecimento. Ambos, em parceria, desenvolvem habilidades de busca, de seleção e de reconstrução do conhecimento mediante a análise crítica e reflexiva.

A pedagogia centrada em projetos funda-se em um novo contrato didático. O papel do aluno é participar colaborativamente de forma ativa, autônoma e responsável no processo ensino-aprendizagem, cabendo ao docente incentivar e orientar o aluno na condução do projeto, compreender o erro como pista essencial de regulação e progresso, promover a 


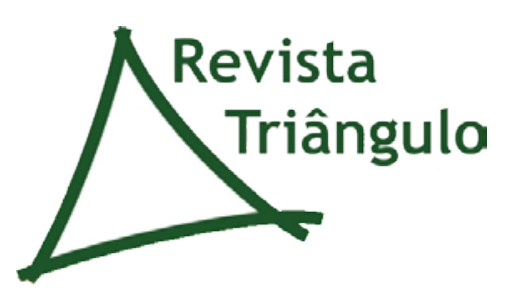

Uberaba, v. 5, n. 2, p. 03-21, jul./dez. 2012. ISSN: 2175-1609

cooperação entre os alunos, ouvir as resistências destes, levá-las em consideração, explicitar e ajustar o contrato didático, engajar-se no trabalho como um par mais experiente.

O currículo por projetos tem uma ênfase mais relacional, mais dialógica, mais culturalcontextual, representando uma nova forma de interagir com o conhecimento, com as pessoas e com as situações de aprendizagem, o que implica humildade, flexibilidade, escuta, responsabilidade social e amorosidade.

\section{CONCLUSÃO}

O referencial teórico e a análise do cenário investigado trouxeram indicadores sobre a possibilidade de conceber o currículo por projetos como uma via interessante para conjugar recursos para uma inovação na educação superior e favorecer a promoção da qualidade da docência.

O currículo por projetos, enquanto teoria curricular crítica, altera e questiona o enfoque curricular hegemônico em um conjunto de aspectos significativos nas dimensões didático-pedagógicas, na estrutura curricular e na dinâmica organizacional e nos aspectos político-culturais.

A abordagem curricular por projetos reúne condições objetivas para que os docentes possam implementar o novo perfil proposto para a docência na atualidade. Uma mudança da abordagem tradicional de currículo para a abordagem curricular por projetos implica uma série de mudanças para o corpo docente. Os papéis e as atividades mudam e também a relação com o conhecimento, com os colegas e alunos. Nesse processo de mudança, os programas de formação são importantíssimos para a inovação, mas o próprio currículo desempenha um papel formador por excelência.

Esperamos ter deixado como contribuição com este trabalho a crença no novo, a coragem e o desejo de fazer do anúncio um prenúncio. 
Uberaba, v. 5, n. 2, p. 03-21, jul./dez. 2012. ISSN: 2175-1609

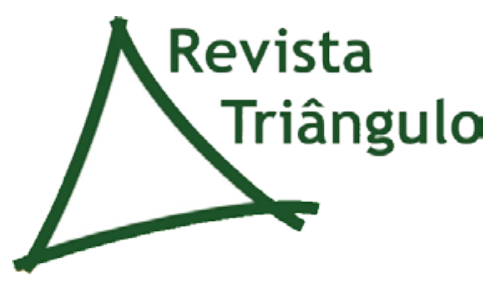

\section{REFERÊNCIAS}

BEANE, A. J. Integração curricular: a essência de uma escola democrática. Currículo sem fronteiras, v.3, n.2, p.91-110, jul./dez. 2003.

BEHRENS, M. A. A interconexão da metodologia de projetos com utilização de recursos informacionais num paradigma da complexidade. In: ENDIPE, 2004, Curitiba: Anais do ENDIPE, 2004a. 2 v.

CASTANHO, M. E. Professores e inovações. In: CASTANHO \& CASTANHO (Orgs.). O que há de novo na educação superior: do projeto pedagógico à prática transformadora. Campinas: Papirus, 2000.

CUNHA, M. I. Aportes teóricos e reflexões da prática: A emergente reconfiguração dos currículos universitários. In: MASETTO, Marcos (Org.). Docência na universidade. 6. ed. Campinas: Papirus, 2003.

FAZENDA, I. Interdisciplinaridade: definição, projeto, pesquisa. In: FAZENDA, I. (Org.). Práticas interdisciplinares na escola. 4 ed. São Paulo: Cortez, 1997.

HERNADEZ, F. Transgressão e mudança na educação: os projetos de trabalho. Porto Alegre: Artmed, 1998b.

KELLER-FRANCO, E. Currículo por projetos: inovação do ensinar e aprender na educação superior. Dissertação (mestrado em Educação:currículo) - Pontifícia Universidade Católica de São Paulo, São Paulo, Brasil, 2008.

LEITE, E.; MALPIQUE, M.; SANTOS, M. R. Trabalho de projecto: aprender por projectos centrados em problemas. 4. ed. Porto: Afrontamento, 2001.

MASETTO, M. T. Competência pedagógica do professor universitário. 2. ed. São Paulo: Summus, 2003.

. Inovação na educação superior. Interface, v.8, n.14, p.197-202,set.2003-fev.2004.

. Um paradigma interdisciplinar para a formação do cirurgião-dentista. In:

CARVALHO, A. C. P.; KRIGER, L. Educação odontológica: São Paulo: Artes Médicas, 2006.

. Inovação Curricular no Ensino Superior. e-curriculum, vol.7, $\mathrm{n}^{\circ}$ 2. Retirado em Abril 20, 2011 de http:/www.pucsp.br/ecurriculum.

PACHECO, J. A. Área de projecto: um componente curricular não-disciplinar. In: LOPES, A. C. ; MACEDO, E. (Orgs.). Disciplinas e integração curricular: história e políticas. Rio de Janeiro: DPEA, 2002. 


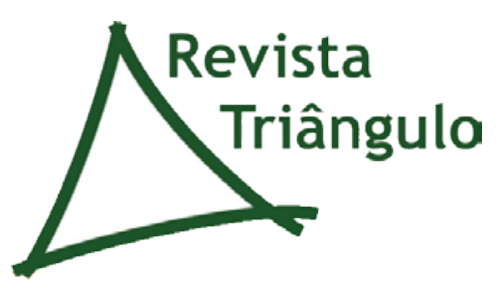

Uberaba, v. 5, n. 2, p. 03-21, jul./dez. 2012. ISSN: 2175-1609

SACRISTÁN, J. G. O currículo: uma reflexão sobre a prática. 3. ed. Porto Alegre: Artmed, 2000.

SANTOMÉ, J. T. Globalização e interdisciplinaridade: o currículo integrado. Porto Alegre: Artes Médicas,1998.

UNIVERSIDADE FEDERAL DO PARANÁ, Unidade Litoral. Relatório de Acompanhamento da Implantação da UFPR Litoral, Matinhos, 2007. 